\title{
Learning Just for the Fun of It: The Case for Video Games
}

\author{
Review of James Gee (2003) What Video Games Have to Teach Us \\ About Learning and Literacy. New York, Palgrave Macmillan. \\ RRP $\$ 66.00$
}

\section{Cal Durrant}

工 ife is full of coincidences. Recently I have been looking at what educational writers have been saying about computer game playing in relation to literacy learning over the past decade. As part of this research I revisited the book I co-edited with Catherine Beavis in 2001 and a chapter by Julian Sefton-Green called 'The "End of School" Or Just "Out of School"?: ICT, the Home and DigitalCultures' in which he explores the world of computer game culture amongst school aged children in the United Kingdom. While watching his six year old son Sam learn how to play Pokemon on the GameBoy console, SeftonGreen made some telling observations about a specific set of literacy practices that have a number of implications for school learning on a far broader scale.

And here's the coincidence. About a month ago I started reading James Gee's latest book What Video Games Have to Teach Us About Learning and Literacy. On the page before his introduction Gee dedicates the book to his six year old son, Sam, whom he tried to help with computer games (You guessed it, Pokemon was one of them!), but who in turn wound up teaching his father how to play and 'to take learning and playing games seriously, all the while having fun'.

While computer and video games have not been without supporters in the educational world (see for example, Beavis 1997, 2002; Buckingham 1993; Buckingham \& SeftonGreen 1994; Nixon 1998; Sanger et al 1997; Shuker 1996; and Zancanella et al 2000), media reports about children playing such games have generally pitched a strong negative message, highlighting the perceived dangers, particularly in relation to the role of violence, the sheer volume of the time investment, and the potential impact on school learning. It is interesting to read James Gee's book in the light of such controversy. Here is a writer from a formal linguistic background who takes the arguments of the opponents of video games and reverses them, using an eclectic though convincing set of theories from general education, learning and psychology.

Many readers will be familiar with Gee's earlier work on literacy learning; for Gee, meaningful learning is always about 'a process of entry into and participation in a Discourse' (Gee, Hull \& Lankshear 1996, 15). In Video Games, the theme is the same, because 'reading and thinking are social achievements connected to social groups' (p.3) and, as the author suggests, we can all read and think differently as members of different groups. In this instance, it is the social group of computer game players, a group that doesn't traditionally spring to mind when we think of the term 'literacy'. And this is where Gee takes issue with traditional thinking about literacy as predominantly being in terms of print. Rather, he suggests that we need to think of literacy as a set of semiotic domains, that is, any group of practices that 'recruits one or more modalities (e.g., oral or written language, images, equations, symbols, sounds, gestures, graphs, artefacts, etc.) to communicate distinctive types of meanings' (p.18). Consequently, we can then reconstruct the term 'literacy' in order to make valid judgements about people being (or not being) literate in a particular semiotic domain if they are able to recognise (i.e., 'read') and/or produce (i.e., 'write') meanings in that domain.

Gee argues that three things are at stake when we learn a new semiotic domain in an active rather than just a passive way (participating in rather than knowing about something):

- we learn to experience the world in new ways;

- we develop the potential to join or affiliate with the groups of people who also engage in this domain as a set of 'distinctive social practices' (p.23);

- we acquire significant resources that enable us to prepare for future learning in that specific domain and perhaps in other related domains.

This experiencing, affiliating and preparing, Gee suggests, is what constitutes active learning. A further step, that of 'critical learning', happens once a person's understanding of a domain reaches the 'meta' level whereby he or she is able to innovate in that domain.

One further observation is needed before looking at Gee's thirty-six principles of learning. Early in the book, he argues that producers (i.e., people who can engage in a particular social practice) make potentially better consumers; in other words, according to Gee writers make better readers than non-writers. He extends this assumption when he distinguishes between internal and external views of a semiotic domain. Any domain, he asserts, can be viewed internally as 'a type of content' or externally in terms of 
'people engaged in a set of social practices' (p.26). Equally, every semiotic domain has what he terms a set of internal and external design grammars. An internal design grammar is the principles and patterns that allow us to recognise what is and what is not acceptable or typical content in a specific semiotic domain. By an external design grammar Gee means the principles and patterns that enable us to recognise what is and what is not acceptable or typical social practice and identity 'in regard to the affinity group associated with that semiotic domain' (p.30). Such a concept has ramifications for any semiotic domain because of the constraints it places on producers and consumers of that domain.

Which brings us to the thirty-six principles.

Gee organises these principles around one very compelling argument, that good video games incorporate self evidently good learning principles simply because if they didn't there would be no video games as too few players would buy and play them (p.114). His thesis is not that what people are learning when they are playing video games is always good, but rather that 'what they are doing when they are playing good video games is often good learning' (p.199). Gee specifies just what he means by giving a number of characteristics of 'good' video games in establishing his principles of learning, principles that he suggests are equally relevant to learning in content areas in school classrooms (p.49).

Space does not allow a thorough description of each principle here, so just as Gee formulates clusters of principles within his six chapters, I will attempt to summarise these in a similar way, always being mindful of course that such a process inevitably leads to simplification of what are in some instances quite complex ideas.

\section{Active and critical learning (Principles 1-5)}

- Good video games are crafted in ways that encourage and facilitate active and critical rather than just passive learning and thinking.

This is not a new concept for educators, though it is interesting to note that in the past, media forms involving screens (and television in particular) have been clearly associated with passive pursuits. More recent work suggests that such is not the case and that a visual grammar may indeed be every bit as complex as any print text grammar (See
Kress \& van Leeuwen 1996). Gee is also quick to point out that just because good games have this design characteristic does not mean that every player will necessarily take up the implicit offer.

\section{Risk taking, identities and achievement (Principles 6-11)}

- Good video games are particularly adept at three things:

o enticing learners to try by encouraging risk taking;

$\circ$ enticing learners to persist by providing compelling environments;

$\circ$ adjusting to the different skill levels represented by individual players and appropriately rewarding them for their efforts.

Gee outlines three identities that are at stake when we play video games. Firstly there is a virtual identity, the identity we take on as a participant character in a game; secondly there is a real world identity, i.e., the non-virtual person playing the game who in life has a number of identities (for James Gee these would include professor, linguist, Anglo American, middle-age male baby boomer, parent, etc.); and thirdly there is what he terms a projective identity - a combination of concepts that means projecting one's non-virtual ideas and values onto the virtual character and seeing the virtual character as one's 'project' in the making and wanting the best possible outcome for that character within the world of the game. As Gee describes it, the stress is on the interface between the real world person and the virtual character. It is at the level of identity where Gee claims that real world baby boomers like him have to face up to the limitations of some of their most cherished ways of thinking and learning because video games do not reward - but can actually punish - such strategies. He lists his own drive to reach a goal without 'engaging in sufficient prior non-linear exploration' as being one such typical limitation (p.57).

Gee argues that people cannot learn in a deep and meaningful way within a semiotic domain if they are 'not willing to commit themselves fully to the learning in terms of time, effort and active engagement' (p.59). Equally, they must sense some reward for the investment of these things in order to continue engaging with their learning; video games 
do this very well while traditional school classrooms often struggle.

\section{Practice and competence (Principles 12-14)}

- Good video games require practice.

Gee's observation here is that human beings need to practise what they are learning in order to master their learning, and equally, acquired skill levels rapidly fall away when such practice ceases. One of his criticisms of school learning is that relevant opportunity is not always given for students to practise their learning. What is more, where it is provided, students often find school related practice thoroughly boring, so they resist it.

- Good video games involve the player in a compelling world of action and interaction, one to which they have made 'an identity commitment' (p.68).

One of the advantages that video games offer over school learning is that players practise a myriad of skills over and over again without realising that they are engaging in extended practice sessions because the player is focused on his or her goals in the game's virtual world, not on the level or amount of practice required to succeed.

- Good video games reward all players who put in effort, but reward players at different skill levels differently, thus helping to blur the distinction between learner and master.

If players routinize their game behaviours, and keep reacting to problems in the same way, a level of the game will be reached where such behaviour is recognised and subsequently disrewarded. This forces players to reflect on their play and undo such routinization in order to achieve higher levels of competency. Such learning cycles allow players to constantly operate at the edge of their competence, a factor that undoubtedly contributes to their continued and often intensified engagement. For Gee, such cycles are rare in school learning, and in many cases the competent learners sit back and coast in 'a curriculum that makes few real demands of them' (p.70).

\section{The probe/hypothesize/re-probe/rethink cycle (Principles 15-18)}

- Good video games require the player to engage in a four-step process:

- probing the virtual world (looking, clicking, etc.);
- hypothesizing about what a text/object/artifact might mean;

- re-probing the world with that hypothesis, and gauging the effects;

- accepting or rejecting the hypothesis based on this feedback.

Gee suggests that we can't get very far in any real world practice if we don't engage in this same step-by-step process, that it is 'the basis of expert reflective practice in any complex semiotic domain'. It works according to Gee because the human mind has 'a wonderful capacity to identify patterns even when such patterns do not exist (e.g. Astrology)' (p.91). As an extension of this argument, Gee raises the subject of reading texts and suggests that texts are not understood purely verbally (i.e., according to the dictionary definitions of the individual words in that text as happens with phonics instruction in learning-to-read programs), but rather in terms of 'embodied experiences', and in order to enhance understanding, readers move back and forth between texts and those embodied experiences (p.108). In this interpretation, strictly verbal understanding only occurs once learners have had sufficient embodied experience in the domain itself and enough contacts with similar texts. School learning usually ignores this principle and concentrates predominantly on verbal understanding of texts as evidence of comprehension.

\section{Multi-modality, material intelligence and intuitive knowledge (Principles 19 -22)}

- Good video games honour not just the explicit and verbal knowledge players have about how to play but also the intuitive and tacit knowledge built into their movements, bodies and unconscious ways of thinking.

Meaning, thinking and learning in video games are linked to multiple modalities, including words, images, actions and sounds. Sometimes these different modalities work together to suggest common meanings, while at other times they can communicate a range of initially confusing meanings. While acknowledging that conscious knowledge is important for critical learning, Gee asserts that, unlike video games, schools tend not to honour the tacit and embodied knowledge that students can build up through practice and adaptation to on-the-spot change. Yet clearly such knowledge is critical in many domains and also explains why game learners feel 
competent in those environments and able to share with their accompanying affinity groups (p.110).

\section{Incremental, bottom-up, on-demand and just-in- time learning (Principles 23-29)}

- Good video games have a special and successful way of dealing with game basics.

Video game players discover what are required 'basic skills' of any game by playing that game. While such basics differ from game to game, there are certain things that are done repeatedly and that combine in quite particular ways in every game. Where the design element is so effective in good video games is that by the time players become aware of these basics, they have already mastered them. As such they are not learned as a set of decontextualized drills or in isolation but as part of their total immersion in the game itself. Information about what they need to know and do is thus available on-demand and just-in-time - at the precise moments when the information can be best understood and practised. Such discovery learning is then likely to serve as useful support for when more complex levels of play are attempted at a later time.

\section{Cultural models, learning and semiotic domains (Principles 30-32)}

- Good video games create whole worlds and invite players to take on various identities.

At least two outcomes can result from players choosing to engage in such worlds: presupposed perspectives on the real world can be reinforced, or they can be challenged. With respect to this particular issue, the potential developments of future game constructions are probably more significant here than their current capacities. Yet even within most current game constructs, players/characters can act for 'good' or 'evil' purposes. In their real world identities, players are faced with decisions about how they should behave with and towards others. Do they act only with the interests of their own group in mind or should they behave in ways that serve the general good? What are 'good' and 'bad' anyway? Gee's argument is that such cultural models, i.e., images, story lines, principles or metaphors that capture what a particular group defines as 'normal' or 'typical' in regard to a given phenomenon, are neither true nor false. Rather, as members of different groups as we live our daily lives we tend to use different cultural models for different situations.

But Gee argues also that these cultural models are 'not just in our heads' (p.145). The words and images of magazines, newspapers and all the other media that surround us 'represent many cultural models'. We also pick them up as 'part and parcel of acting with others in the world' (p.146). Inevitably as we move among different members of different groups, such cultural models come into conflict, and Gee suggests that consequently video games have a powerful potential for letting people experience the world from quite different cultural, moral and ethical perspectives. Just as in the real world, players are forced to make sense of their circumstances and surroundings; it is in their making sense of virtual worlds - not just in thought but also in action - that enables players to experience new and different cultural models. The problem arises of course when players are recruited to particular extremist political causes: who does (or should) dictate just what identities we can enact in virtual worlds? Should games like Ethnic Cleansing be available? Gee is quick to admit that he has no answers to such searching questions. In the light of 9/11 and its aftermath, I would suggest that such questions are desperately in need of addressing.

\section{Distributed and dispersed knowledge, affinity groups and 'insiders' (Principles 33-36)}

- Goodvideogameplayers experienceamore intenseaffinity group, leverage more knowledge from other people, tools and technologies and are more powerfully networked with each other than they ever are in school.

In his final chapter, Gee explores the idea that thinking and reasoning are inherently distributed, that is, each of us lets other people and various tools and technology do some of our thinking for us. For Gee the power resides not so much in storing content knowledge but knowing how to access it when you need it. By definition, then, such thinking and reasoning are also social because clearly players are part of a game-playing network of other players who help one another solve problems, gain progress and succeed. Knowledge, then, is both distributed across the learner, objects, tools, symbols, etc. and also dispersed as the learner shares with others both inside and outside of the semiotic domain of video game playing. Those with whom he or 
she finds a common interest and passion for video games constitute an affinity group, and it is with this group that the learner is recognisable as an 'insider'. However, the game designer is not the 'insider' and the player an 'outsider', as so often happens in the traditional classroom; rather, game designers and players 'are both insiders and there need be no outsiders' at all (p.194).

What Video Games Have to Teach Us is an enormously interesting and challenging book. Throughout, Gee deals a number of telling blows against traditional school learning as he identifies some of the sound design and pedagogical elements characteristic of what he identifies as 'good' video games. Of course, not all teachers and school classrooms operate in the way that he caricatures school learning. Those that care only about 'what is inside students' heads', those that believe that those same heads and bodies 'are isolated from others, from tools and technologies' and from 'rich environments that help make them powerful nodes in networks' are in Gee's words, 'DOA [dead on arrival] in our current world - and kids who play video games know it' (p.189). This book serves as a strident warning to educational communities outside of the United States that are considering following the Yellow Brick Road towards skill-and-drill, back-to-basics, test-them-till-you-drop schooling so often espoused by their business and political leaders. There is a better path, according to Gee, and good video games serve as important signposts towards the sort of learning design that helps change lives.

\section{REFERENCES}

Beavis, C. (1997) 'Computer games, culture and curriculum', in Snyder, I. (ed) Page to Screen: Taking Literacy into the Electronic Era. St Leonards, Allen \& Unwin.

(2002) 'Reading, writing and roleplaying computer games', in Snyder, I. (ed) Silicon Literacies: Communication, Innovation and Education in the Electronic Age. London, Routledge.

Buckingham, D. (1993) 'Just playing games'. The English and Media Magazine 28: 21-25.

Buckingham, D. \& Sefton-Green, J. (1994) Cultural Studies Goes to School: Reading and
Teaching Popular Media. London, Taylor and Francis.

Gee, J., Hull, G. \& Lankshear, C. (1996) The New Work Order: Behind the Language of the New Capitalism. Boulder, Col, Westview.

Goodwyn, A. (1992) English Teaching and Media Education. Buckingham, Open University Press.

Kress, G. \& van Leeuwen, T. (1996) Reading Images: The Grammar of Visual Design, London, Routledge.

Nixon, H. (1998) 'Fun and games are serious business', in Sefton-Green, J. (ed) Digital Diversions: Youth Culture in the Age of Multimedia. London, UCI Press.

Sanger, J., Wilson, J., Davies, B. \& Whittaker, R. (1997) Young Children, Videos and Computer Games: Issues for Teachers and Parents, London, Falmer.

Sefton-Green, J. (2001) 'The "end of school” or just "out of school"?: ICT, the home and digital cultures', in Durrant, C. \& Beavis, C. (eds) P(ICT)ures of English: Teachers, Learners and Technology. Adelaide, Wakefield.

Shuker, R. (1996) 'Video games: serious fun'. Continuum 9, 2: 125-45.

Zancanella, D, Hall, L. \& Pence, P. (2000) 'Computer games as literature', in Goodwyn, A. (ed) English in the Digital Age: Information and Communications Technology and the Teaching of English. London, Cassell.

\section{BIOGRAPHICAL NOTE}

Cal Durrant is Chair of the Initial Teacher Education (Secondary)program and lectures in English Curriculum and MediaEducation at Murdoch University. His major research is in the areas of English literacy and technology and his most recent publication is a co-edited book with Catherine Beavis entitled P(ICT) ures of English: Teachers, learners and technology published by Wakefield Press (2001). 